\title{
Maternal Serum Zinc Level and Pre-eclampsia Risk in African Women: a Systematic Review and Meta-analysis
}

\author{
Endalamaw Tesfa ${ }^{1,2}$ (1) $\cdot$ Endalkachew Nibret ${ }^{2,3} \cdot$ Abaineh Munshea $^{2,3}$ \\ Received: 22 November 2020 / Accepted: 24 January 2021 / Published online: 1 February 2021 \\ (C) The Author(s) 2021
}

\begin{abstract}
Some studies have reported the association between maternal serum zinc $(\mathrm{Zn})$ levels and pre-eclampsia. However, many studies have reported controversial results. Hence, this systematic review and meta-analysis was planned to generate summarized evidence on the association between maternal serum $\mathrm{Zn}$ levels and pre-eclampsia in African women. Four electronic databases such as PubMed, Hinari, Google Scholar, and African Journals Online were searched for studies published in English. Joanna Briggs Institute Meta-Analysis of Statistics Assessment and Review Instrument, and Newcastle-Ottawa Scale were used for data extraction and quality assessment of the included studies. The meta-regression analysis was performed by the Stata 14 software. The standardized mean difference (SMD) values of lipid profiles were computed to assess their association with pre-eclampsia at $95 \%$ CI. A total of 12 observational studies were included. The mean values of serum $\mathrm{Zn}$ level were significantly lower in preeclamptic women as compared with normotensive pregnant women $(\mathrm{Zn}=59.40 \pm 22.80 \mu \mathrm{g} / \mathrm{dL}$ and $80.24 \pm 16.04 \mu \mathrm{g} / \mathrm{dL})$, respectively. The pooled SMD of $\mathrm{Zn}$ was significantly reduced in pre-eclamptic women as compared with normotensive pregnant women with the SMD of -1.45 (95\% CI - 2.26, -0.65) at 95\% CI. In this review, we found that the maternal $\mathrm{Zn}$ serum level was significantly reduced in pre-eclamptic women than normotensive pregnant women. This suggests that $\mathrm{Zn}$ could be involved in the etio-pathogenesis of pre-eclampsia. However, the specific functions of $\mathrm{Zn}$ in pre-eclampsia pathogenesis should be proved in large-scale clinical trial studies.
\end{abstract}

Keywords Zinc $\cdot$ Pre-eclampsia $\cdot$ Meta-analysis $\cdot$ Africa

\section{Introduction}

Pre-eclampsia is a multi-system condition occurring after 20 weeks of gestation. It is clinically characterized by new onset of hypertension and proteinuria. Globally, pre-eclampsia is one of the major cause of maternal and prenatal morbidity

Endalamaw Tesfa

endalamaw2009@gmail.com; endalamaw.tesfa@bdu.edu.et

Endalkachew Nibret

endtg2002@yahoo.com

Abaineh Munshea

abitew2003@yahoo.com

1 Department of Biochemistry, College of Medicine and Health Sciences, Bahir Dar University, Bahir Dar, Ethiopia

2 Biotechnology Research Institute, Bahir Dar University, Bahir Dar, Ethiopia

3 Department of Biology, College of Science, Bahir Dar University, Bahir Dar, Ethiopia and mortality [1]. In Ethiopia, pre-eclampsia is also the commonest direct cause of maternal and prenatal deaths [2]. Despite continuing research, the pathogenesis of this disorder is still unclear and delivery of the placenta remains the only cure. Evidences from animal and human studies so far have shown that abnormal placentation, diffuse endothelial cell dysfunction, and increased systemic inflammation contributed to the pathogenesis of pre-eclampsia [3]. Micronutrient deficiencies are common in pregnant women which lead to preeclampsia development [4]. Human exposure to excess toxic metals in the environment and deficiency of bio-elements essential for antioxidant defense mechanisms causes oxidative stress, which leads pre-eclampsia [5].

Zinc ( $\mathrm{Zn}$ ) is the second most abundant trace element next to iron which is essential for all living organisms. It exists as a divalent cation and is not redox active under physiological conditions, which explains why zinc performs different physiological roles in a variety of biological processes [6]. $\mathrm{Zn}$ is served as the structural components and cofactors of different classes of enzymes [7]. Zinc is an essential trace element for human nutrition that is an integral part of many enzyme 
systems like DNA polymerase complex [8]. $\mathrm{Zn}$ is involved in different signaling pathways [9]. Zn deficiency has been associated with different diseases like pre-eclampsia, different types of cancer [10], cardiovascular disease [11, 12], skin disease, immunity [9, 13], aging [13], and infection [14]. Zn is important for normal pregnancy and fetal development $[15$, $16]$ and its deficiency during pregnancy or in early childhood period leads to stunting, mental retardation, and delayed sexual maturity $[8,17]$.

Many studies have tried to explore the association between the serum levels of $\mathrm{Zn}$ in pre-eclampsia, but many of them have reported conflicting results. Some studies have shown significant low levels of $\mathrm{Zn}$ in pre-eclamptic women as compared to normotensive pregnant women [18-20]. However, some studies have found that the serum $\mathrm{Zn}$ concentration was not varying significantly between the two groups [21-23]. Therefore, the present systematic review and metaanalysis was planned to generate summarized evidence on the association between maternal serum $\mathrm{Zn}$ levels and preeclamptic in African women.

\section{Methods and Materials}

\section{Protocol and Registration}

This review protocol is registered at the National Institute for Health Research: PROSPERO international prospective register of systematic reviews with registration number CRD42020203746 at https://www.crd.york.ac.uk/prospero/\# recordDetails.

\section{Study Design and Search Strategy}

A systematic review and meta-analysis of published studies were conducted to assess the association between maternal serum levels of zinc and pre-eclampsia. We searched the following databases: PubMed, Hinari, African Journals Online (AJOL), and Google Scholar. The search was done by using Medical Subject Heading (MeSH) terms: "Serum, Zinc, Zn, trace elements, Pre-eclampsia AND Africa" separately or in combination. All published articles up to August 31, 2020, were retrieved and assessed for their eligibility for their inclusion in this review. Preferred Reporting Items for Systematic Reviews and Meta-Analyses (PRISMA) guideline was utilized to conduct this systematic review and meta-analysis.

\section{Eligibility Criteria}

\section{Inclusion and Exclusion Criteria}

1. Studies conducted in African pre-eclamptic women were included.
2. Studies with case-control, comparative cross-sectional, and cohort designs were included.

3. Articles that report pre-eclampsia as an outcome variable were included.

4. Published and unpublished articles written in English were included.

5. Studies reporting serum levels of Zinc in mean and standard deviation were included.

6. Conference papers, editorials, reviews, and randomized control trials were excluded.

\section{Study selection and screening}

All citations identified by our search strategy were exported to EndNote-X9 and duplicate articles were removed. And then the titles and abstracts of the identified articles were screened by two independent reviewers, and eligible studies were included for further review. The full texts of selected articles were retrieved and read thoroughly to ascertain the suitability prior to data extraction. In case of disagreement between the two reviewers, discussion was held to reach consensus and the third reviewer was consulted. The search process was presented in the PRISMA flow chart that clearly shows the studies that were included and excluded with reasons of exclusion (Fig. 1) [24].

\section{Definition of Outcome Interest}

The primary outcome of this study was to evaluate the association between the maternal serum levels of $\mathrm{Zn}$ with preeclampsia in African women.

- Hypertension is defined as the systolic blood pressure $\geq 140 \mathrm{mmHg}$ (SBP) and/or diastolic blood pressure $\geq 90 \mathrm{mmHg}$ and measured at least two times within 4-h interval.

- Proteinuria: urinary protein excretion of $\geq 300 \mathrm{mg} / 24 \mathrm{~h}$ urine sample or $\geq 1+$ on qualitative dipstick examination or a total protein: creatinine ratio $\geq 30 \mathrm{mg} / \mathrm{mmol}$ (or $\geq 0.3$ when both are measured in $\mathrm{mg} / \mathrm{dL}$ ).

- Gestational hypertension: hypertension diagnosed after 20 weeks of gestation.

- Pre-eclampsia is defined as hypertension plus proteinuria after 20 weeks of gestation.

- Eclampsia: seizures in women with hypertension that cannot be attributed to other causes [25].

\section{Quality Assessment}

For case-control studies, we used the Newcastle-Ottawa Scale (NOS) to assess the quality of the included studies while for 
Fig. 1 Flow diagram showing the eligibility of studies included in this review

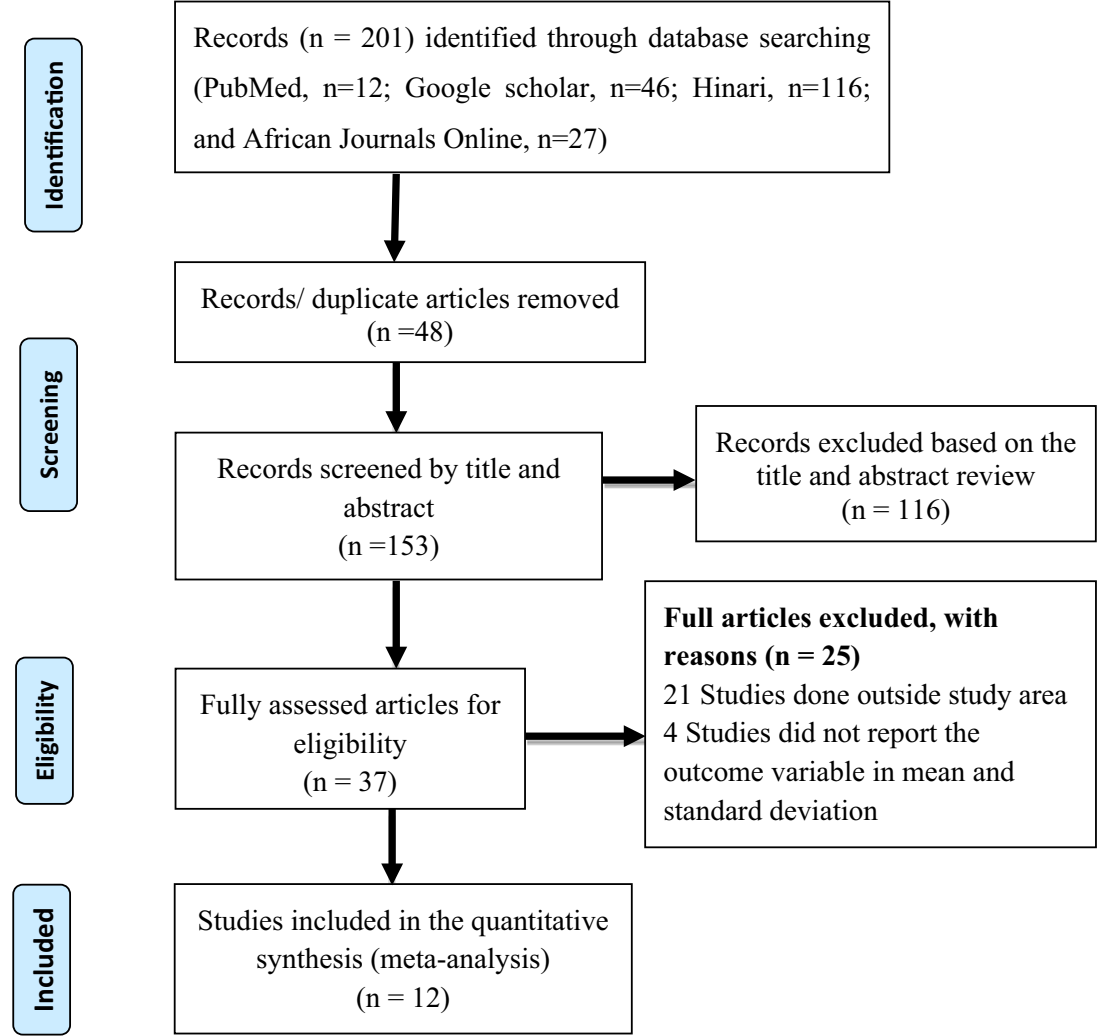

cross-sectional studies, the modified version of NOS was used to assess the quality of the studies for inclusion [26]. The NOS included 3 categorical criteria with a maximum score of 9 points. The quality of each study was rated using the following algorithm scoring: $\geq 6$ points was considered "Good," 4 to 5 points was considered "Fair," and $\leq 3$ point was considered "Poor" quality study. Accordingly, in order to improve the validity of this systematic review result, we only included primary studies with fair to good quality [26].

\section{Data Extraction Process}

The data extraction was done using a tool developed by the 2014 Joanna Briggs Institute Reviewers' Manual data extraction form [27]. The abstract and full-text were reviewed by the two independent reviewers. Data extraction includes author's name, publication year, study country, study design, sample size, number of cases and controls, mean age, mean gestational age, mean body mass index (BMI), mean SBP, mean DBP, and mean Zn level. Zn results reported other than $\mu \mathrm{g} / \mathrm{dL}$ were changed by multiplying their conversion factors.

\section{Data Analysis}

The data were entered into Microsoft Excel and the metaanalysis was performed using the Stata 14 software and
SPSS. Forest plot of SMD was used to assess the strength of association between the serum levels of $\mathrm{Zn}$ and pre-eclampsia at $95 \%$ CI. The SMD is the ratio of the mean difference to the pooled standard deviation. Standard error of mean (SEM) calculated by the formula $\mathrm{SEM}=\mathrm{SD} / \sqrt{ } n$. Subgroup analysis was done by country (Nigeria, Sudan, Egypt, Kenya, and Zambia). Variables like maternal age, gestational age, BMI, mean SBP, mean DBP, and mean $\mathrm{Zn}$ level were analyzed.

\section{Heterogeneity and Publication Bias}

Statistical heterogeneity was estimated through Cochrane's $Q$, $I^{2}$ statistic, and $P$ value. $I^{2}$ statistic values $<25 \%, 25-50 \%$, and $\geq 50 \%$ were used to declare the heterogeneity test as low, medium, and high heterogeneity. In this review, random effect model (REM) was used for analysis. To cope with the reasons of heterogeneity, subgroup analysis and sensitivity test were performed. Publication bias was assessed through Egger's test and funnel plot.

\section{Results}

\section{Study Selection}

A total of 201 articles were retrieved through electronic search by using different search terms of which 153 article were 
eligible for title and abstract assessment after removal of 48 duplicate records. Out of 153 articles screened for eligibility, 116 records were excluded by their title and abstract assessment. A total of 33 articles underwent full-text assessment for eligibility, and 25 studies were excluded due to different reasons (21 articles were done outside the study area and four studies did not report the result in mean and standard deviation).

\section{Study Characteristics}

In this review, a total of 12 studies were included [5, 19-21, 23, 28-34]. Nine of them were case-control [19-21, 29-34] and three studies [5, 23, 28] were cross-sectional. Studies that have been conducted in Africa and published up to August 31, 2020, were included. Five studies were done in Nigeria, three in Sudan, two in Egypt, and the other two studies were done in Kenya and Zambia. In this review, a total of 1599 pregnant women were included (775 cases and 824 controls) (Table 1).

\section{Association of Different Variables with Pre-eclampsia}

In this analysis, we compared the mean values of variables among pre-eclamptic and normal control groups. Statistical significant difference was not observed between the two groups with regard to the mean values of women's age, gestational age, BMI, and DBP. However, statistical significant differences were found in the mean values of SBP and serum
$\mathrm{Zn}$ level between the two groups [5, 19-21, 23, 28-34] (Table 2).

\section{Association of Zinc with Pre-eclampsia}

In this sub-categorical analysis, 12 studies were included to compare the serum $\mathrm{Zn}$ level between pre-eclampsia and normotensive pregnant women. Seven of the included studies showed significantly lower serum levels of $\mathrm{Zn}$ in preeclamptic than normotensive pregnant women [5, 19, 20, 29-32]. However, five studies showed non-significant association between the serum levels of $\mathrm{Zn}$ and pre-eclampsia [21, 23, 28, 33, 34]. Pooled meta-regression analysis showed that the serum levels of $\mathrm{Zn}$ is statistically decreased in preeclamptic women as compared with normotensive pregnant women with a pooled SMD of -1.45 (95\% CI $-2.26,-0.65)$ (Fig. 2).

\section{Sensitivity Analysis and Publication Bias}

A sensitivity test was done by omitting one study at a time to assess the stability of the results. There was no significant change in the pooled SMD after excluding one of the studies at $95 \%$ CI (Supporting file 1). This means there is no individual study that excessively influence on the pooled effects of the serum $\mathrm{Zn}$ level and risk of pre-eclampsia. Funnel plot did not show evidence of publication bias between maternal serum $\mathrm{Zn}$ levels and pre-eclampsia (Fig. 3). And also, Egger's test did not show evidence of publication bias and its $P$ value was 0.319 .

Table 1 Characteristics of research articles included in the systematic review and meta-analysis $(N=12)$

\begin{tabular}{|c|c|c|c|c|c|c|c|c|c|}
\hline No & Authors & Country & Study design & Total & PE & NP & $\mathrm{Zn} \mathrm{PE}, \mu \mathrm{g} / \mathrm{dL}($ mean $\pm \mathrm{SD})$ & $\mathrm{Zn} \mathrm{NP}, \mu \mathrm{g} / \mathrm{dL}($ mean $\pm \mathrm{SD})$ & $\begin{array}{l}\text { Quality } \\
\text { score }\end{array}$ \\
\hline 1 & Mohamed et al. 2019 [20] & Egypt & Case-control & 50 & 25 & 25 & $60.8 \pm 12.8$ & $95.70 \pm 10.40$ & 5 points \\
\hline 2 & Pulei et al. 2018 [33] & Kenya & Case-control & 108 & 54 & 54 & $64.74 \pm 24.2$ & $69.98 \pm 22.89$ & 6 points \\
\hline 3 & Elmugabil et al. 2016 [21] & Sudan & Case-control & 100 & 50 & 50 & $108 \pm 23.21$ & $102 \pm 27.02$ & 6 points \\
\hline 4 & Chababa et al. 2016 [28] & Zambia & Cross-sectional & 98 & 41 & 57 & $89.17 \pm 47.2$ & $76.20 \pm 35.23$ & 6 points \\
\hline 5 & Ikaraoha et al. 2016 [19] & Nigeria & Case-control & 209 & 59 & 150 & $45.8 \pm 9.70$ & $68.2 \pm 10.10$ & 5 points \\
\hline 6 & Onyegbule et al. 2016 [32] & Nigeria & Case-control & 102 & 54 & 48 & $54.08 \pm 3.92$ & $79.52 \pm 11.97$ & 6 points \\
\hline 7 & Eldaem et al. 2016 [29] & Sudan & Case-control & 200 & 100 & 100 & $17.77 \pm 23.2$ & $99.24 \pm 27.02$ & 6 points \\
\hline 8 & Hassan et al. 2014 [31] & Sudan & Case-control & 201 & 122 & 79 & $49.4 \pm 17.0$ & $90.3 \pm 16.80$ & 6 points \\
\hline 9 & Akinloye et al. 2010 [5] & Nigeria & Cross-sectional & 89 & 49 & 40 & $56.24 \pm 9.16$ & $61.47 \pm 5.23$ & 5 points \\
\hline 10 & $\begin{array}{l}\text { El-Moselhy et al. } 2010 \\
\quad[30]\end{array}$ & Egypt & Case-control & 200 & 100 & 100 & $60.81 \pm 9.74$ & $95.7 \pm 12.41$ & 6 points \\
\hline 11 & Ugwuja et al. 2010 [34] & Nigeria & Case-control & 80 & 40 & 40 & $65.20 \pm 63.70$ & $71.09 \pm 67.23$ & 5 points \\
\hline 12 & Enebe et al. 2020 [23] & Nigeria & Cross-sectional & 162 & 81 & 81 & $40.80 \pm 39.0$ & $53.50 \pm 80.0$ & 6 points \\
\hline
\end{tabular}

$N P$ normal pregnant, $P E$ pre-eclampsia, $S D$ standard deviation, $\mu g / d L$ microgram per deciliter, $Z n$ zinc 
Table 2 Paired sample test association of variables with $\mathrm{PE}$

\begin{tabular}{llllll}
\hline S. No & Variable & Studies & Cases $(N=775)$ & Controls $(N=824)$ & $P$ value \\
\hline 1 & Age in year (mean $\pm \mathrm{SD})$ & 6 & $27.78 \pm 2.72$ & $27.74 \pm 1.48$ & 0.974 \\
2 & GA in week $($ mean $\pm \mathrm{SD})$ & 4 & $31.70 \pm 7.06$ & $31.56 \pm 6.92$ & 0.504 \\
3 & BMI $($ mean $\pm \mathrm{SD})$ & 4 & $28.61 \pm 1.92$ & $27.66 \pm 2.20$ & 0.057 \\
4 & SBP $($ mean $\pm \mathrm{SD})$ & 5 & $160.27 \pm 14.61$ & $115.38 \pm 3.89$ & $0.006^{* *}$ \\
5 & DBP $($ mean $\pm \mathrm{SD})$ & 5 & $83.08 \pm 40.62$ & $72.95 \pm 3.43$ & 0.604 \\
6 & Zinc $(\mu \mathrm{g} / \mathrm{dL})$ & 12 & $59.40 \pm 22.80$ & $80.24 \pm 16.04$ & $0.016^{* *}$ \\
\hline
\end{tabular}

$B M I$ body mass index, $D B P$ diastolic blood pressure, $G A$ gestational age, $S B P$ systolic blood pressure, $S D$ standard deviation, $\mu g / d L$ microgram per deciliter

**Statistically significant at $P<0.05$

\section{Discussion}

This is the first compressive systematic review and metaanalysis of studies evaluating the association between the serum levels of $\mathrm{Zn}$ with pre-eclampsia as compared to normotensive pregnant women in Africa. In this study, maternal age, gestational age, and DBP were comparable between the two groups and these variables showed nonstatistical significant association with pre-eclampsia. The mean SBP and mean maternal serum level of zinc were significantly associated with pre-eclampsia as compared to normotensive pregnant women.

In this review, the mean serum zinc level was significantly reduced in pre-eclamptic women as compared to normotensive pregnant women $(59.40 \pm 22.80 \mu \mathrm{g} / \mathrm{dL}$ and $80.24 \pm 16.04$ $\mu \mathrm{g} / \mathrm{dL})$, respectively, and its pooled SMD of $\mathrm{Zn}$ was $(\mathrm{SMD}=$ $-1.45,95 \%$ CI $-2.26,-0.65)$. Similar finding was reported in systematic review and meta-analysis conducted in China [35]. In the studies conducted in Saudi Arabia and India, the serum levels of zinc were also significantly lower in pre-eclamptic women as compared with normotensive pregnant women [18, 36]. $\mathrm{Zn}$ deficiency is observed in almost $17 \%$ of the global population and affects many organ systems which causes malfunction of both the humoral and cell-mediated immunity [37].

$\mathrm{Zn}$ is an essential metal and served as the structural components of many structural proteins and the cofactors for several metalloenzymes [38]. $\mathrm{Zn}$ is required during pregnancy for placental morphogenesis and maternal blood pressure regulation and its deficiency impairs fetal growth and blood pressure
Fig. 2 Forest plot of SMD of serum Zinc level in pre-eclampsia

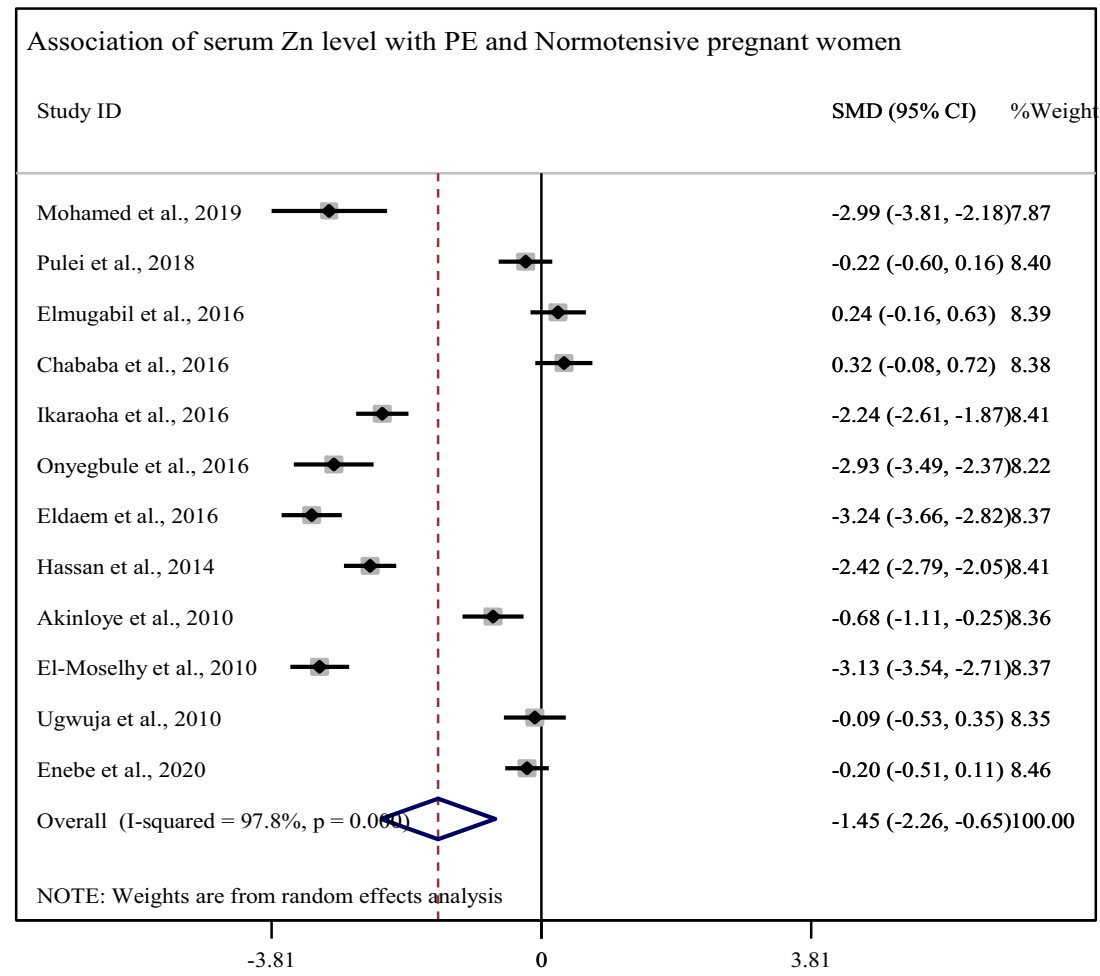




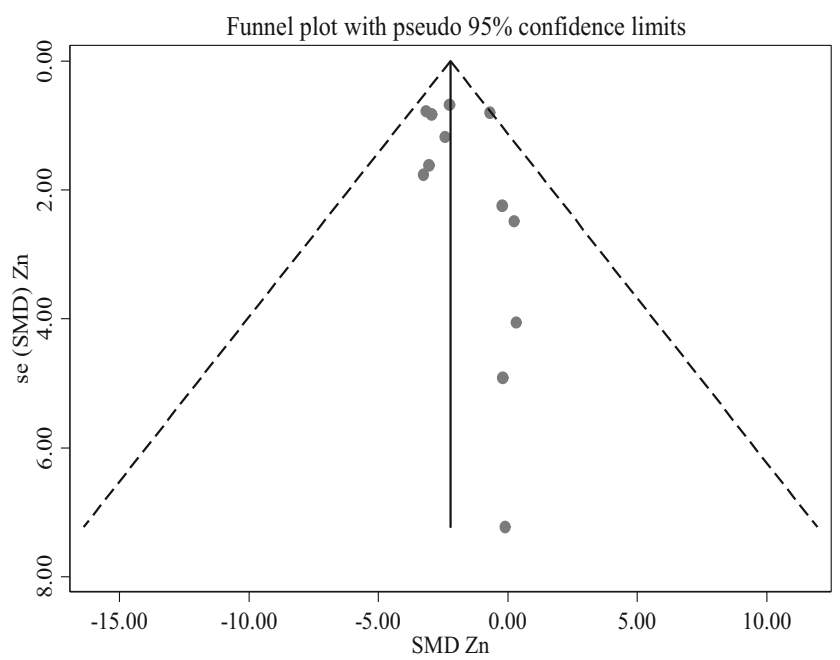

Fig. 3 Funnel plot of serum levels of Zinc in pre-eclampsia

abnormalities. Animal model experimental studies proved that zinc deficiency leads to abnormal placental morphogenesis and maternal blood pressure [39]. Zn also involved in the cellular neuronal systems and its deficiency may severely affect the homeostasis of a biological system [40]. Available data suggested that $\mathrm{Zn}$ had a significant function in spermatogenesis, embryogenesis, fetal development, and maintaining deoxyribonucleic acid (DNA) integrity. High or low level of zinc concentration might have significant impact on sperm and egg development [41].

$\mathrm{Zn}$ is involved in stability of membrane structure, DNA transcription, protein transport systems, and signaling pathways [42]. It is a multipurpose trace element, which binds to more than 300 enzymes and 2000 transcriptional factor proteins [37]. $\mathrm{Zn}$ is required for the synthesis of protein and collagen, which contributes to wound healing and a healthy skin [37]. Zn deficiency results major health consequences such as severe defects in growth, development, and proper functioning of the reproductive, immune, and neurosensory systems and in behavior [43]. Its deficiency may contribute for tumor progression via increased expression of the nuclear factor kappa B (NF-kB)-dependent pro-tumorigenic cytokines and impaired in $\mathrm{Zn}$ homeostasis which has been observed in different forms of cancers [10]. Inadequate nutritional intake, decreased absorption, or increased loss of zinc all are responsible for zinc deficiency [12].

Increased production of free radicals and reduced levels of some trace elements disrupt the antioxidant defense mechanisms, which contributed oxidative stress. In this review, the serum $\mathrm{Zn}$ level was decreased in pre-eclamptic women than normal controls; the mechanism how $\mathrm{Zn}$ deficiency causes pre-eclampsia is not clearly understood. However, animal model studies suggested that $\mathrm{Zn}$ deficiency may induce high blood pressure by promoting sodium reabsorption by increasing $\mathrm{Na}^{+}-\mathrm{Cl}^{-}$cotransporter expression [44]. Zn deficiency in prenatal and postnatal rats induces blood pressure derangement accompanied by cardiovascular and renal morphological and functional changes [45].

This systematic review and meta-analysis generates pooled data that showed the association between serum levels of $\mathrm{Zn}$ in African pre-eclamptic women. In addition, this review served as baseline information for further study but this study is not free from limitations. The first limitation was related to our literature search strategy, and we included articles published in English, and this could lead to reporting bias. Most of the included studies were from Nigeria, and this may influence its generalizability. Moreover, presence of high statistical heterogeneity among the included studies would decrease the evidence of the review.

\section{Conclusion}

In this systematic review and meta-analysis, the mean serum levels of $\mathrm{Zn}$ was significantly reduced in pre-eclamptic women as compared with normotensive pregnant women. Pooled SMD of serum $\mathrm{Zn}$ level was also significantly reduced in preeclamptic women as compared with normal pregnant women. Thus, $\mathrm{Zn}$ could play certain roles in the pathogenesis of preeclampsia. However, concrete evidences on the functions of $\mathrm{Zn}$ and risk of pre-eclampsia pathogenesis in African women would require large-scale studies.

Supplementary Information The online version contains supplementary material available at https://doi.org/10.1007/s12011-021-02611-7.

Author contributions ET: conceptualization, data curation, formal analysis, methodology, writing original draft, writing review, and editing. AM: conceived the review topic, reviewed the protocol, supervised the review process, reviewed, investigated, and validated the final manuscript. EN: involved in analysis, software work, and reviewing and validating the final manuscript. All authors read and approved the final draft of the manuscript

Data Availability All data pertaining to this study are contained and presented in this document and in the supplementary files.

\section{Declarations}

Conflict of interest The authors declare that they have no competing interests.

Abbreviations BMI, Body mass index; CI, Confidence interval; DBP, Diastolic blood pressure; DNA, Deoxyribonucleic acid; GA, Gestational age; JBI-MAStARI, Joanna Briggs Institute Meta-Analysis of Statistics Assessment and Review Instrument; $\mu \mathrm{g} / \mathrm{dL}$, Microgram per deciliter; NOS, Newcastle-Ottawa Scale; PE, Pre-eclampsia; PRISMA, Preferred reporting items for systematic reviews and meta-analyses; RR, Risk ratio; SBP, Systolic blood pressure; SD, Standard deviation; SEM, Standard error of mean; SMD, Standardized mean difference; Zn, Zinc 
Open Access This article is licensed under a Creative Commons Attribution 4.0 International License, which permits use, sharing, adaptation, distribution and reproduction in any medium or format, as long as you give appropriate credit to the original author(s) and the source, provide a link to the Creative Commons licence, and indicate if changes were made. The images or other third party material in this article are included in the article's Creative Commons licence, unless indicated otherwise in a credit line to the material. If material is not included in the article's Creative Commons licence and your intended use is not permitted by statutory regulation or exceeds the permitted use, you will need to obtain permission directly from the copyright holder. To view a copy of this licence, visit http://creativecommons.org/licenses/by/4.0/.

\section{References}

1. Sánchez-Aranguren LC, Prada CE, Riaño-Medina CE, Lopez M (2014) Endothelial dysfunction and preeclampsia: role of oxidative stress. Front Physiol 5:1-11

2. Tesfa E, Nibret E, Gizaw ST, Zenebe Y, Mekonnen Z, Assefa S, Melese M, Fentahun N, Munshea A (2020) Prevalence and determinants of hypertensive disorders of pregnancy in Ethiopia: a systematic review and meta-analysis. PLoS One 15(9):e0239048

3. Phipps E, Prasanna D, Brima W, Jim B (2016) Preeclampsia: updates in pathogenesis, definitions, and guidelines. Clin J Am Soc Nephrol 11(6):1102-1113

4. Achamrah N, Ditisheim A (2018) Nutritional approach to preeclampsia prevention. Curr Opin Clin Nutr Metab Care 21(3): $168-173$

5. Akinloye O, Oyewale OJ, Oguntibeju OO (2010) Evaluation of trace elements in pregnant women with pre-eclampsia. Afr $\mathrm{J}$ Biotechnol 9(32):5196-5202

6. Kambe T, Tsuji T, Hashimoto A, Itsumura N (2015) The physiological, biochemical, and molecular roles of zinc transporters in zinc homeostasis and metabolism. Physiol Rev 95(3):749-784

7. Baltaci AK, Yuce K, Mogulkoc R (2017) Zinc metabolism and metallothioneins. Biol Trace Elem Res 183(1):22-31

8. Jeejeebhoy K (2009) Zinc: an essential trace element for parenteral nutrition. Gastroenterology 137(5 Suppl):S7-S12

9. Haase H, Rink L (2009) Functional significance of zinc-related signaling pathways in immune cells. Annu Rev Nutr 29:133-152

10. Gumulec J, Masarik M, Adam V, Eckschlager T, Provaznik I, Kizek R (2014) Serum and tissue zinc in epithelial malignancies: a meta-analysis. PLoS One 9(6):e99790

11. Arnaud J, Touvier M, Galan P, Andriollo-Sanchez M, Ruffieux D, Roussel AM, Hercberg S, Favier A (2010) Determinants of serum zinc concentrations in a population of French middle-age subjects (SU.VI.MAX cohort). Eur J Clin Nutr 64(10):1057-1064

12. Choi S, Liu X, Pan Z (2018) Zinc deficiency and cellular oxidative stress: prognostic implications in cardiovascular diseases. Acta Pharmacol Sin 39(7):1120-1132

13. Haase H, Rink L (2009) The immune system and the impact of zinc during aging. Immun Ageing 6:9

14. Gammoh NZ, Rink L (2017) Zinc in infection and inflammation. Nutrients 9(6):1-25

15. Osendarp SJM, West CE, Black RE (2003) The need for maternal zinc supplementation in developing countries: an unresolved issue. J Nutr 133:817S-827S

16. Raimi OG, Falade OA, Folorunso OS, Lawal AK (2012) Zinc and iron levels in pregnancy: a review. Pakistan J Food Sci 22(2):53-60

17. Freak HC, Sankavaram K (2013) Physiology, Dietary sources and Requirements. Encyc Hum Nutr 4:1-7

18. Kanagal DV, Rajesh A, Rao K, Shetty H, Shetty PK, Ullal H (2014) Zinc and copper levels in preeclampsia: a study from coastal South India. Int J Reprod Contracept Obstet Gynecol 3(2):370-373
19. Ikaraoha IC, Mbadiwe NC, Ojareva IA (2016) Serum trace metals in pre-eclamptic Nigerians. Asian J Med Sci 7(3):78-83

20. Mohamed ASS, El-Omda FA, Abdelfatah AT, Hashish MA (2019) Comparative study for serum zinc and copper levels in cases with normal pregnancy versus preeclampsia. Egypt J Hosp Med 74(5): 1069-1074

21. Elmugabil A, Hamdan HZ, Elsheikh AE, Rayis DA, Adam I, Gasim GI (2016) Serum calcium, magnesium, zinc and copper levels in Sudanese women with preeclampsia. PLoS One 11(12): $1-8$

22. Rafeeinia A, Tabandeh A, Khajeniazi S, Marjani AJ (2014) Serum copper, zinc and lipid peroxidation in pregnant women with preeclampsia in Gorgan. Open Biochem J 8:83-88

23. Enebe JT, Dim CC, Ugwu EO, Enebe NO, Meka IA, Obioha KC, Eleje GU, Nwagha UI (2020) Serum antioxidant micronutrient levels in pre-eclamptic pregnant women in Enugu, south-East Nigeria: a comparative cross-sectional analytical study. BMC Pregnancy Childbirth 20(1):392

24. Moher D, Liberati A, Tetzlaff J, Altman DG (2009) Preferred reporting items for systematic reviews and meta-analyses: the PRISMA statement. PLoS Med 6(7):e1000097

25. Chaiworapongsa T, Chaemsaithong P, Yeo L, Romero R (2014) Pre-eclampsia part 1: current understanding of its pathophysiology. Nat Rev Nephrol 10(8):466-480

26. Hartling L, Milne A, Hamm MP, Vandermeer B, Ansari M, Tsertsvadze A, Dryden DM (2013) Testing the Newcastle Ottawa Scale showed low reliability between individual reviewers. J Clin Epidemiol 66(9):982-993

27. Joanna BI (2014) Joanna Briggs Institute Reviewers' Manual 2014 edition: Joanna Briggs Institute: 1-40

28. Chababa L, Mukosha M, Sijumbila G, Vwalika B (2016) Relationship between serum zinc levels and preeclampsia at the University Teaching Hospital, Lusaka, Zambia. Med J Zambia 43(3):139-144

29. Eldaem AEN, Ismael S, ObeidOmer EA (2016) Assessment of trace elements, total white blood cells and platelets count in pregnant ladies with preeclampsia in Sudan. Lab Med J 2:1

30. El-Moselhy EA, Amin HH, Abd El-Aal HM (2010) Maternal serum calcium and trace elements; copper and zinc among preeclamptic wowmen in Cairo, Egypt. Egypt J Hosp Med 41:520-531

31. Hassan EE, Elhhatim W, Bakhit SM, Shrif NE, Huneif MA (2016) Assessment of trace elements in Sudanese pre-eclamptic pregnant women. Eur J Biomed Pharmaceut Sci 1(2):13-21

32. Onyegbule AO, Onah CC, Iheukwumere BC, Udo JN, Atuegbu CC, Nosakhare NO (2016) Serum copper and zinc levels in preeclamptic Nigerian women. Niger Med J 57(3):182-184

33. Pulei AN, Kinuthia J, Ogutuc O (2018) Serum levels of selected micronutients in primigravida with pre-eclampsia versus their normotensive counterparts: a case control study at a teritiary teaching hospital in Kenya. Int J Med Health Sci 4(4):9-17

34. Ugwuja EI, Ejikeme BN, Ugwu NC, Obeka NC (2010) Comparison of plasma copper, iron and zinc levels in hypertensive and non-hypertensive pregnant women in Abakaliki, South Eastern Nigeria. Pak J Nutr 9(12):1136-1140

35. Zhu Q, Zhang L, Chen X, Zhou J, Liu J, Chen J (2016) Association between zinc level and the risk of preeclampsia: a meta-analysis. Arch Gynecol Obstet 293(2):377-382

36. Al-Jameil N, Tabassum H, Al-Mayouf H, Aljohar HI, Alenzi ND, Hijazy SM, Khan FA (2014) Analysis of serum trace elementscopper, manganese and zinc in preeclamptic pregnant women by inductively coupled plasma optical emission spectrometry: a prospective case controlled study in Riyadh, Saudi Arabia. Int J Clin Exp Pathol 7(5):1900-1910

37. Chasapis CT, Ntoupa PA, Spiliopoulou CA, Stefanidou ME (2020) Recent aspects of the effects of zinc on human health. Arch Toxicol 94(5):1443-1460 
38. Noonan CW, Kathman SJ, Sarasua SM, White MC (2003) Influence of environmental zinc on the association between environmental and biological measures of lead in children. J Expo Anal Environ Epidemiol 13(4):318-323

39. Wilson RL, Leemaqz SY, Goh Z, McAninch D, JankovicKarasoulos T, Leghi GE, Phillips JA, Colafella KM, Tran C, O'Leary S et al (2017) Zinc is a critical regulator of placental morphogenesis and maternal hemodynamics during pregnancy in mice. Sci Rep 7(1): 15137

40. Kaur K, Gupta R, Saraf SA, Saraf SK (2014) Zinc: the metal of life. Compr Rev Food Sci Food Saf 13(4):358-376

41. Murarka S, Mishra V, Joshi P, Sunil K (2015) Role of zinc in reproductive biology - an overview. Austin J Reprod Med Infertil 2(2):01-08

42. O'Dell BL (2000) Role of zinc in plasma membrane function. Am Soc Nutr Sci 130:1432S-1436S
43. Lee SR (2018) Critical role of zinc as either an antioxidant or a prooxidant in cellular systems. Oxidative Med Cell Longev 2018(9156285):1-11

44. Williams CR, Mistry M, Cheriyan AM, Williams JM, Naraine MK, Ellis CL, Mallick R, Mistry AC, Gooch JL, Ko B, Cai H, Hoover RS (2019) Zinc deficiency induces hypertension by promoting renal Na(+) reabsorption. Am J Physiol Renal Physiol 316(4):F646F653

45. Sato M, Yanagisawa H, Nojima Y, Tamura J, Wada O (2002) Zn Deficiency aggravates hypertension in spontaneously hypertensive rats: a possible role of $\mathrm{Cu} / \mathrm{Zn}$ - Superoxide dismutase. Clin Exp Hypertens 24(5):355-370

Publisher's Note Springer Nature remains neutral with regard to jurisdictional claims in published maps and institutional affiliations. 